\title{
Benzalkonium chloride breaks down conjunctival immunological tolerance in a murine model
}

\author{
JG Galletti ${ }^{1,2}$, ML Gabelloni $^{1}$, PE Morande ${ }^{1}$, F Sabbione $^{1}$, ME Vermeulen $^{1}$, AS Trevani ${ }^{1}$ and \\ MN Giordano ${ }^{1}$
}

The impact of topical eye drops with benzalkonium chloride (BAK) as a preservative could involve more than the reported toxic effects on the ocular surface epithelium and ultimately affect the immune balance of the conjunctiva. We found that BAK not only impairs tolerance induction in a murine model, but leads to mild systemic immunization. Contrasting with antigen only-treated mice, there was no induction of interleukin 10-producing antigen-specific $\mathrm{CD}^{+}$cells in BAK-treated animals. Moreover, the tolerogenic capacity of migrating dendritic cells (DCs) was reduced, apparently involving differential conditioning by soluble epithelial factors. Accordingly, epithelial cells exposed in vitro to BAK were less suppressive and failed to induce tolerogenic DCs in culture. As this effect of BAK was dependent on epithelial nuclear factor $\mathrm{KB}$ pathway activation, our findings may provide new therapeutic targets. Thus, tolerance breakdown by BAK should be considered an important factor in the management of glaucoma and immune-mediated ocular surface disorders.

\section{INTRODUCTION}

Ocular surface disorders represent a frequent complaint in ophthalmological practice ${ }^{1}$ and range from allergic reactions, which cause mild discomfort to sight-threatening diseases such as cicatricial pemphigoid and Steven-Johnson's syndrome. Despite the disparate presentations and prognosis, an immune dysfunction of the ocular mucosa, the conjunctiva, underlies most of these clinical entities. ${ }^{2}$ Because of this, eye surface disease is frequently treated with topical eye drop formulations containing an active compound, such as corticosteroids, and a preservative (usually $0.01 \%$ benzalkonium chloride, BAK) that prevents bacterial colonization of the preparation. ${ }^{3}$ More important, glaucoma patients are often given BAK-containing formulations daily for years, leading to treatment-induced chronic inflammation or potentiation of an underlying ocular surface disease. There are many reported side effects of topical treatment, most of which have been ascribed to the widely explored toxic effects of BAK on the ocular surface, and specifically, on the epithelial cells, ${ }^{4-7}$ and limited to morphological and phenotypical aspects of ocular surface toxicity. ${ }^{8}$ In line with this, Liang et al. ${ }^{9}$ recently described increased inflammatory cell infiltration in the conjunctiva of rabbits treated with this preservative. Surprisingly, the impact of these toxic effects of BAK on the immunological function of the conjunctiva has not been addressed before.

The conjunctiva, as every other mucosa lining the inner surface of the body, is capable of mounting vigorous immune responses against pathogens, but under normal conditions, it keeps harmful inflammation at bay by inducing tolerance to the irrelevant antigens to which it is heavily exposed. ${ }^{10}$ Although the underlying molecular and cellular mechanisms for conjunctival tolerance have not been fully explored, it is highly probable that they resemble those described for the nasal mucosa. ${ }^{11}$ According to the prevailing model, ${ }^{12}$ the mucosal microenvironment, and more specifically, the surface epithelium, ${ }^{13}$ programs the antigenloaded dendritic cells (DCs) migrating to the draining lymph node (LN) to induce either tolerogenic (regulatory) or immunogenic (effector) T-cell expansion. Thus, the immune decision whether to induce tolerance or immunization occurs at the mucosal surface and the detection of danger signals is paramount to this outcome. Both epithelial cells and DCs can sense danger by recognizing not only pathogen-associated molecular patterns, ${ }^{14}$ but also endogenous signals derived from cell damage ${ }^{15}$ and it is becoming increasingly clear that the crosstalk between epithelial and DCs is a key element in mucosal immunity. ${ }^{16,17}$

${ }^{1}$ Immunology Laboratory, Institute of Experimental Medicine (IMEX), National Academy of Medicine, Buenos Aires, Argentina. ${ }^{2}$ Ophthalmology Division, Hospital de Clínicas, University of Buenos Aires, Buenos Aires, Argentina. Correspondence: JG Galletti (jeremiasg@gmx.net)

Received 3 January 2012; accepted 26 April 2012; published online 13 June 2012. doi: 10.1038/mi.2012.44 

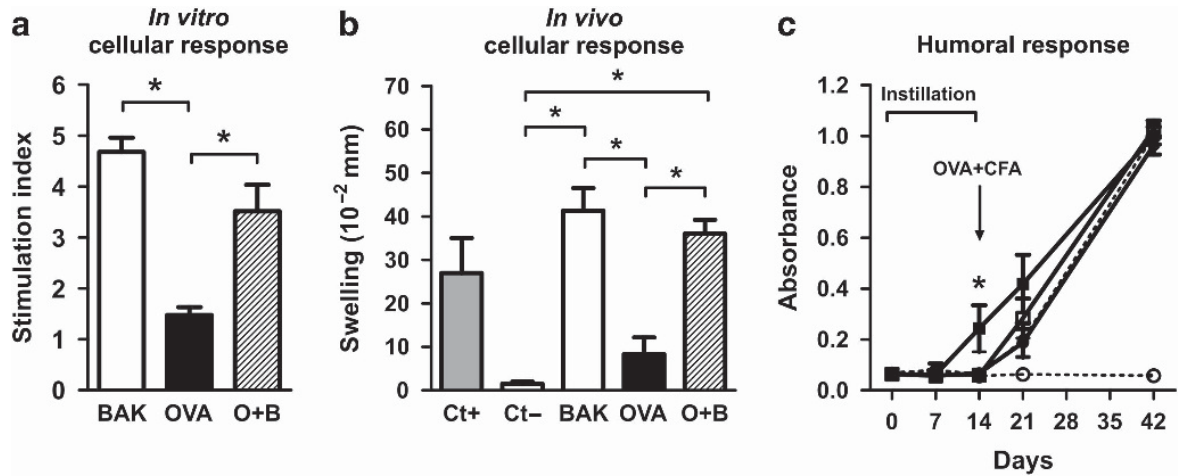

Figure 1 Effect of benzalkonium chloride (BAK) on conjunctival tolerance. BAK (empty bars), ovalbumin (OVA; black bars) or both (O+B, hatched bars) were delivered daily to each eye of groups of mice $(n=3)$ for 5 days, then the animals were immunized parenterally with OVA in adjuvant. (a) OVA-specific proliferation (mean stimulation index \pm s.e.m.) of splenocytes obtained 7 days after immunization with OVA +CFA (complete Freund's adjuvant). (b) In vivo delayed-type hypersensitivity response tests expressed as mean swelling \pm s.e.m. (in $\left.10^{-2} \mathrm{~mm}\right)$. Ct+ (grey bar) and $\mathrm{Ct}-$ (empty bar) refer to control groups (no conjunctival instillation) with OVA+CFA or PBS (phosphate-buffered saline) +CFA immunization, respectively. (c) Enzyme-linked immunosorbent assay (mean absorbance \pm s.e.m.) for serum anti-OVA immunoglobulin $G$ antibody levels from groups of mice $(n=3)$ treated with BAK (empty squares), OVA (filled squares), O+B (filled circles) for 2 weeks, then immunized with OVA+CFA. Animals were bled weekly along with control unimmunized (empty circles) and immunized-only mice (filled circles, dotted line). Asterisk indicates a statistically significant difference.

As epithelial cells from other mucosal sites are crucial in determining the fate of the immune response, ${ }^{18,19}$ it is plausible that BAK, beyond inducing direct cell damage, could impair the conjunctival epithelium's capacity to maintain tolerance and thus negatively impact on the course and treatment of the many ocular surface disorders that share an immunological pathophysiology. Therefore, the aim of this work was to evaluate the functional impact of BAK exposure on conjunctival tolerance in mice, and specifically address the effect of this preservative on the conditioning role of the conjunctival epithelium.

\section{RESULTS}

\section{BAK impairs the development of conjunctival tolerance}

By using a previously validated conjunctival tolerance model involving ovalbumin (OVA), we evaluated the effect of concurrent BAK instillation on antigen exposure. Mice were administered OVA alone or in the presence of $0.01 \%$ BAK in both eyes, and then systemically challenged with the same antigen plus adjuvant. By evaluating antigen-specific cell proliferation in vitro (Figure 1a), we found that tolerance to OVA was readily induced after 5 days of treatment, but not if the antigen was delivered simultaneously with BAK. Similar results were obtained by measuring the delayed-type hypersensitivity response in vivo (Figure 1b), supporting this claim. Both Balb/c and C57BL/6 mice, which differ markedly in their immune responses to model antigens, were used in these experiments to account for any background-specific effects. We observed no differences in tolerance/immunity induction between mouse strains, and therefore chose to continue with $\mathrm{Balb} / \mathrm{c}$ mice. As described for oral tolerance, ${ }^{20}$ conjunctival instillation of antigen did not impair subsequent OVA-specific immunoglobulin $\mathrm{G}$ antibody production after parenteral immunization (Figure 1c). Conjunctival tolerance for cellular responses was accompanied by a small but detectable rise in antigen-specific antibody titer, which has also been reported for oral tolerance. ${ }^{20}$ Additionally, and as expected, BAK administration per se had no effect on the cellular and humoral responses to OVA induced by parenteral immunization.

\section{BAK prevents the induction of regulatory $T$ cells}

As conjunctival tolerance could be ascribed to the induction of either T-cell anergy or regulatory T cells, we analyzed the antigen-specific response in the draining LNs and spleen in both the treatment groups before systemic challenge. As shown in Figure 2a, no OVA-specific proliferation could be elicited in vitro in LN cells from OVA-treated mice, whereas a low but consistent response was detected in the OVA + BAK group. Similar results were obtained with spleen cells, indicating that $\mathrm{T}$ cells induced by treatment were already recirculating at this timepoint. $\mathrm{T}$ cells from OVA-treated mice at increasing ratios significantly reduced the antigen-induced proliferation of splenocytes from an immunized mouse, as would regulatory T cells, whereas those from OVA + BAK mice significantly augmented this response, suggesting the presence of effector $\mathrm{T}$ cells (Figure 2b). As T cells isolated from OVA or OVA + BAK mice were functionally opposite in their response to OVA, we hypothesized that disparate Foxp3 expression and/or cytokine production could explain these results. However, no significant differences could be observed in the proportion of Foxp $3^{+}$or cytokine-producing T cells in the draining LN (data not shown), probably owing to the low numbers of antigenspecific cells involved in this model. To better discriminate any potential small changes, we expanded in vivo-induced T cells by culturing in the presence of antigen-loaded DCs to increase the proportion of OVA-specific $\mathrm{T}$ cells. We found that $\mathrm{T}$ cells from the OVA + BAK group showed increased production of IFN $\gamma$ (interferon $\gamma$ ) and interleukin (IL)-4, but not IL-10, compared with those from the OVA group (Figure 2c, left panel, and Figure 2d). Thus, this strategy seemed to expand effector cytokine-producing T cells in the OVA + BAK group, but these 
a

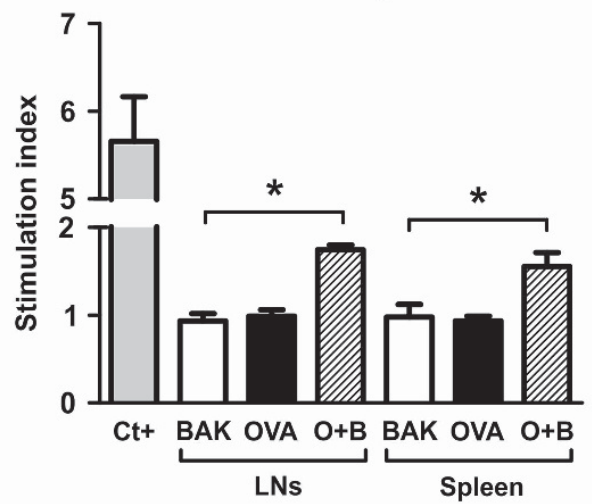

b

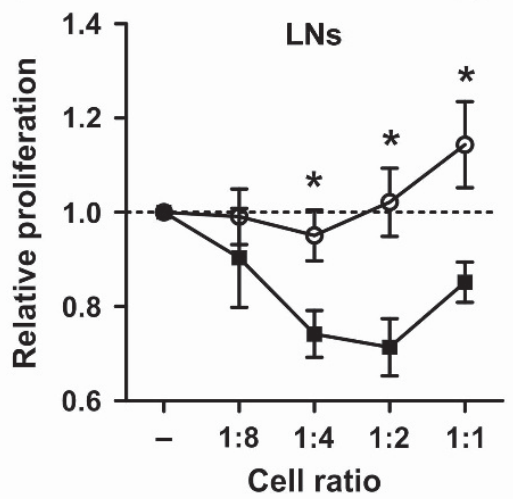

Suppression curves

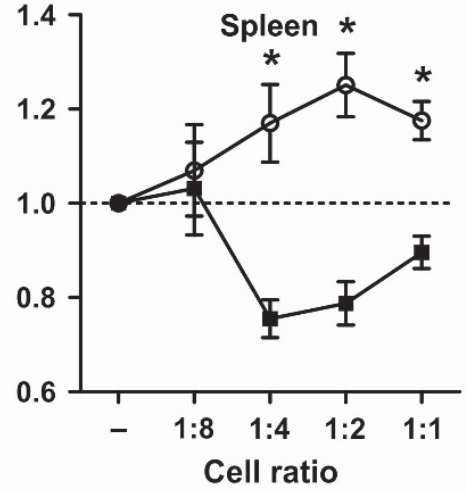

OVA-specific cytokine production

C

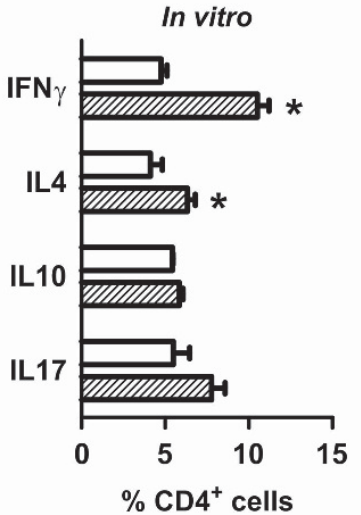

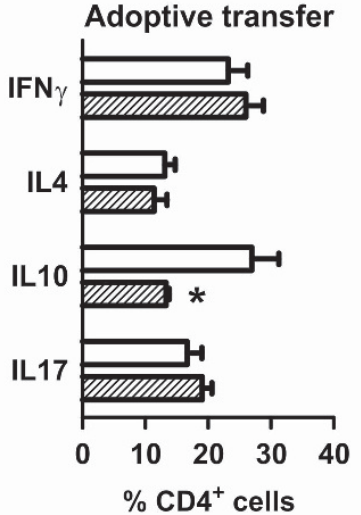

$\% \mathrm{CD}^{+}$cells

e

Foxp3 \& ICOS expression
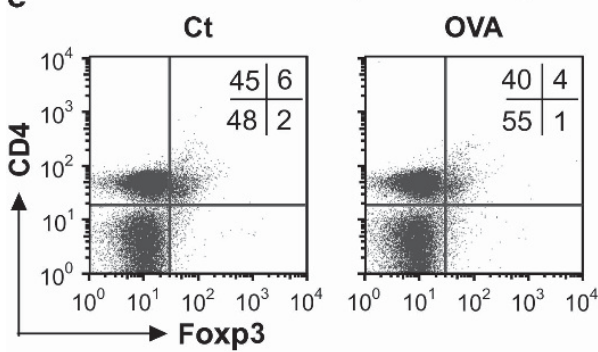

\section{OVA+BAK}
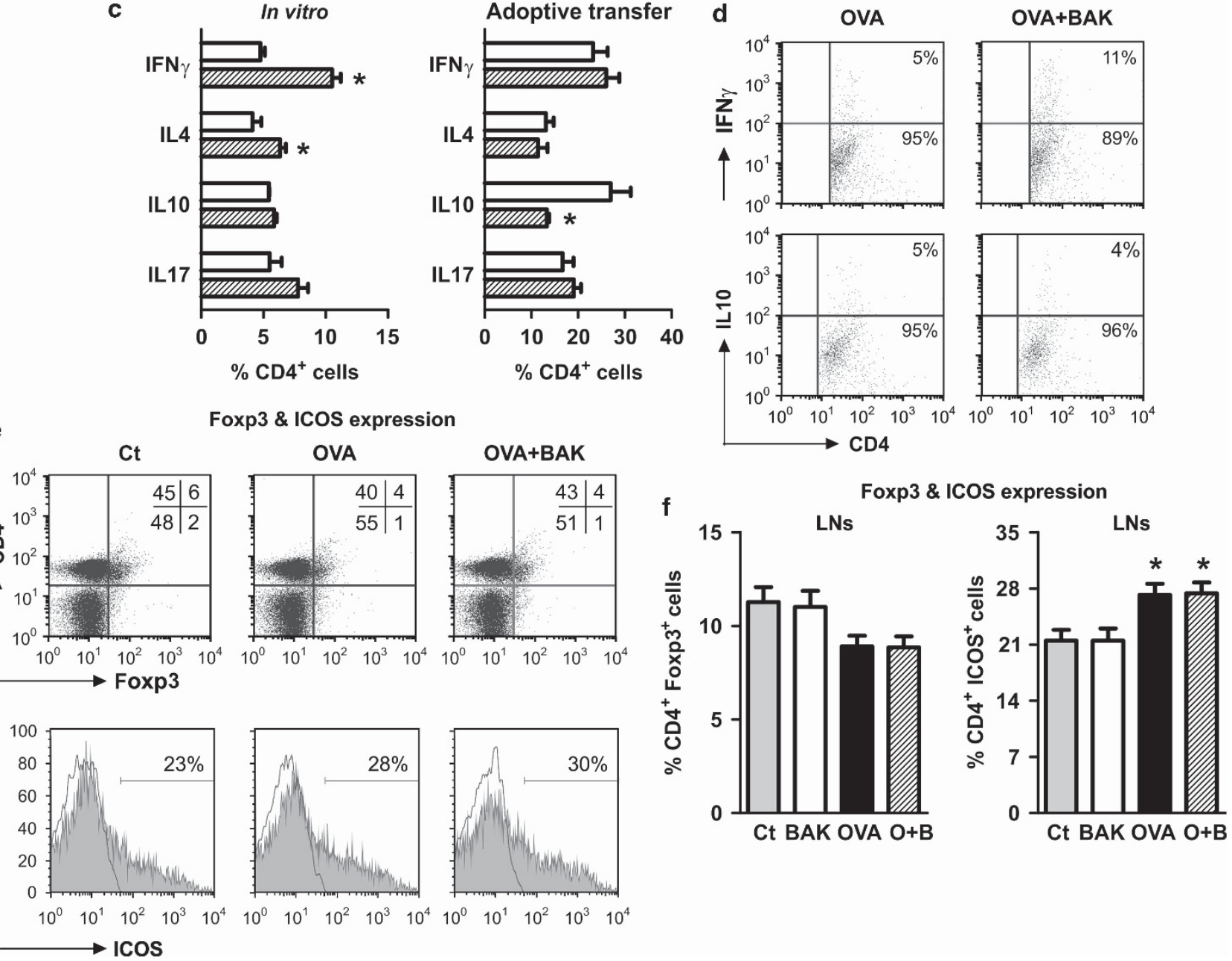

Figure 2 Effect of benzalkonium chloride (BAK) on the ovalbumin (OVA)-specific T-cell response. Lymph node (LN) and spleen cells from groups of mice $(n=3)$ were obtained on day 7 after 5 days of conjunctival instillation. (a) OVA-specific proliferation (mean stimulation index \pm s.e.m.) of LN and spleen cells.

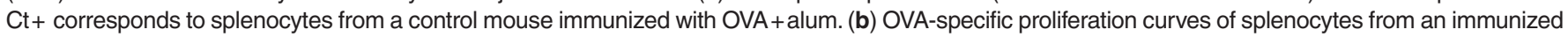
mouse with increasing numbers of LN or splenic CD4 ${ }^{+}$cells from OVA (filled squares) or OVA+BAK (empty circles) mice. Data (mean \pm s.e.m.) are expressed relative to the stimulation indexes of cultures with the same ratio of added cells from BAK-treated mice. (c) Cytokine production by LN cells from OVA (empty bars) and OVA+BAK-treated mice (hatched bars). Data presented as mean percentage \pm s.e.m. of cytokine-producing CD4+ lymphocytes. Cells for the in vitro measurements were harvested after 5 days of conjunctival instillation, while those from adoptively transferred mice were obtained on day 3. (d) Representative dot plots (CD4 ${ }^{+}$gate) of the in vitro measurements described in c. (e) LN cells from adoptively transferred mice on day 3 were assayed for Foxp3 and inducible T-cell costimulator (ICOS) expression (representative dot plots and histograms). Ct corresponds to adoptively transferred mice that only were treated with BAK. (f) Percentage (mean+s.e.m.) of Foxp3 ${ }^{+}$and ICOS ${ }^{+}$cells in the LN CD4 ${ }^{+}$population of adoptively transferred animals. Ct corresponds to untreated transferred mice and $\mathrm{O}+\mathrm{B}$ corresponds to OVA+BAK treatment. For all experiments, asterisk indicates a statistically significant difference and no less than 3 mice were included in each treatment group. Each experiment was performed at least three times. 
findings seemed insufficient to explain the previously observed suppressive capacity of $\mathrm{T}$ cells from OVA mice. To account for any artifacts induced by in vitro stimulation with bone marrow-derived DCs (BMDC) and to better assay for the induced changes in vivo, we evaluated the draining LN cells from mice that were adoptively transferred with transgenic OVA-specific $\mathrm{CD} 4{ }^{+}$cells. On day 3 of conjunctival instillation, we found increased production of IL-10, but not IFN $\gamma$, IL-4, and IL-17 in the transferred $\mathrm{T}$ cells from OVA-treated mice (Figure 2c, right panel), confirming the aforementioned findings and suggesting the induction of antigen-specific IL-10-secreting T cells by conjunctival antigen alone. No increase in the proportion of $\mathrm{CD} 4^{+}$ Foxp $3^{+}$cells in the draining LN at this time point (Figure 2e,f, top panels) or later (day 5, data not shown) could be detected, although a statistically significant increase in inducible T-cell costimulator + (ICOS, CD278) cells (a marker of Tr1 regulatory and Th2 effector cells) was observed in both the treatment groups compared with untreated transferred mice (Figure 2e,f, bottom panels). From both functional and cytokine production viewpoints, these results altogether show that OVA + BAK instillation induces a different $\mathrm{T}$-cell profile (non-suppressive Foxp3 ${ }^{-}$, ICOS ${ }^{+}$, effector cytokine-secreting cells) than the administration of antigen alone (suppressive Foxp3- ${ }^{-} \mathrm{ICOS}^{+}$, IL-10-producing cells).

\section{BAK indirectly modifies the functional profile of DCs migrating from the conjunctiva}

To assess whether the observed changes in systemic tolerance and T-cell induction after BAK instillation could be due to an effect on the DCs migrating from the conjunctiva to the draining LNs, we tracked cell migration by applying OVAFITC (fluorescein-conjugated OVA) to both eyes of mice. As seen in Figure 3a, BAK did not significantly increase the number of OVA-FITC ${ }^{+}$DCs $\left(\mathrm{CD} 11 \mathrm{c}^{+} \mathrm{Ia}^{+}\right)$or the amount of protein taken up by these cells (evaluated as mean fluorescence intensity of OVA-FITC ${ }^{+}$cells). However, BAK-conditioned migrating DCs were more efficient at inducing T-cell proliferation (Figure 3b) than basal-state migrating DCs, suggesting a non-tolerogenic profile. In agreement with this functional difference, we observed augmented expression of Ia molecules and a reduction in ICOS ligand (ICOSL) costimulatory molecules in the LN DCs of mice exposed to BAK (Figure 3c). Other costimulatory molecules, such as CD40 and CD86, were not significantly modulated in vivo by this treatment. Considering that a direct effect of BAK could explain the observed differences in conjunctival DC conditioning, we set up an experiment to model BAK exposure. To this aim, BAK at three different concentrations (that used in vivo and two 10-fold dilutions) was added to BMDCs for $15 \mathrm{~min}$, washed, and the cells were left overnight in culture before adding allogeneic $\mathrm{T}$ cells to assess their stimulatory capacity. In contrast to the findings with ex vivo BAK-conditioned DCs, BMDCs exposed to BAK in vitro showed reduced allostimulatory function, partially due to a toxic effect of the preservative on these cells (Figure 3d). As this negative effect could even be observed with the lowest BAK concentration (100-fold lower than that used in vivo), we concluded that the increased allostimulatory capacity of BAK-conditioned DCs could not be ascribed to a direct effect of the preservative on these antigen-presenting cells (APCs). Quite the contrary, these results suggest that BAK instillation indirectly modifies the functionality and phenotype of DCs migrating from the conjunctiva to the draining LN.

\section{BAK impairs the tolerogenic influence of the conjunctiva and epithelial cells}

As DCs migrating from the conjunctiva were found to be functionally affected by BAK, we hypothesized that the conjunctival epithelium was responsible for the programming of these APCs, as it has been proposed for other mucosal sites. ${ }^{18,19}$ To test this hypothesis, we obtained conjunctival explants from control and BAK-treated mice for 5 days and set up overnight cultures to collect supernatants (SNs). Assayed by their influence on the mixed lymphocyte reaction (MLR), control SNs were more suppressive than BAK SNs (Figure 4a), although both had a negative impact on the allogeneic reaction. This effect was mediated by inhibition of the MLR proliferation, not by induction of cell death, as no differences in viability (by 7 -amino-actinomycin D staining, flow cytometry) could be observed in separate splenocyte cultures in the presence of the assayed SNs (see Supplementary Figure 1A online). As conjunctival explants could harbor different populations of immune cells along with epithelial and stromal cells that would influence this result, we attempted to grow primary cultures of murine conjunctival epithelial cells. These cells could be cultured in vitro over a feeder fibroblast monolayer for one or two passages, but we were unable to obtain the large number of cells required for the following experiments. As there are no commercially available murine keratinocyte cell lines from conjunctival origin, we proceeded to grow Pam 212 cells, ${ }^{21}$ a widely characterized skin keratinocyte cell line that shares many morphological features with conjunctival epithelial cells. Pam 212 cells were exposed to different BAK concentrations for $15 \mathrm{~min}$ to simulate conjunctival instillation and then thoroughly washed, as has been proposed by others. ${ }^{22,23}$ Overnight-conditioned SNs were collected and assayed as for conjunctival explant SNs. In agreement with previous reports, ${ }^{22}$ a slight reduction in cell viability and no distinct morphological changes were observed with the two lowest BAK concentrations, whereas $0.01 \%$ BAK induced extensive cell death and marked cellular changes (Figure $\mathbf{4 b}, \mathbf{c}$ ). Regarding the release of soluble factors (Figure 4d), control Pam212 SNs were highly suppressive of the MLR, whereas 0.0001 and $0.001 \%$ BAK SNs showed less activity or none at all. As previously observed with conjunctival explant SNs, none of these SNs had an effect on cell viability, assayed by 7 -amino-actinomycin $\mathrm{D}$ staining in splenocyte cultures (see Supplementary Figures 1B,C online). SNs derived from $0.01 \%$ BAK-exposed cells, which were not viable, were even more suppressive than control SNs. This effect, which was also observed with other cell-death-inducing treatments (freeze-thaw cycle, 5-fluorouracil and fludarabine, Figure 4d), seems to be independent of BAK and rather the influence of extensive necrosis and apoptosis. Remarkably, lipopolysaccharide- and poly I:C-derived SNs, two different Toll-like receptor 

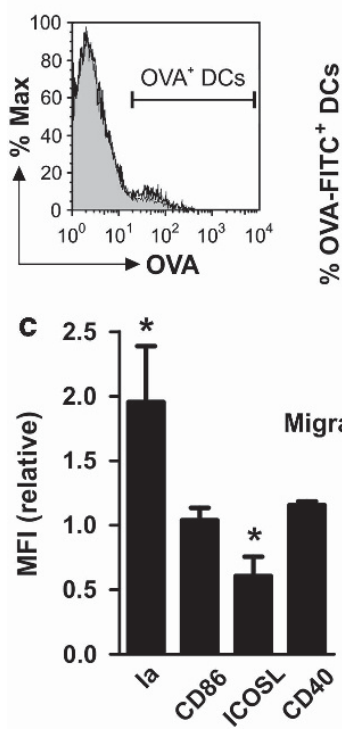

DC migration \& OVA uptake

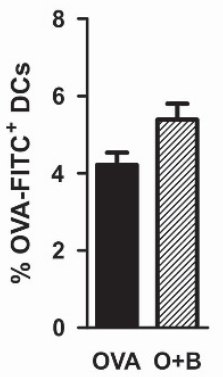

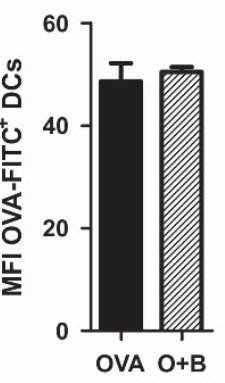

b Allogeneic stimulation
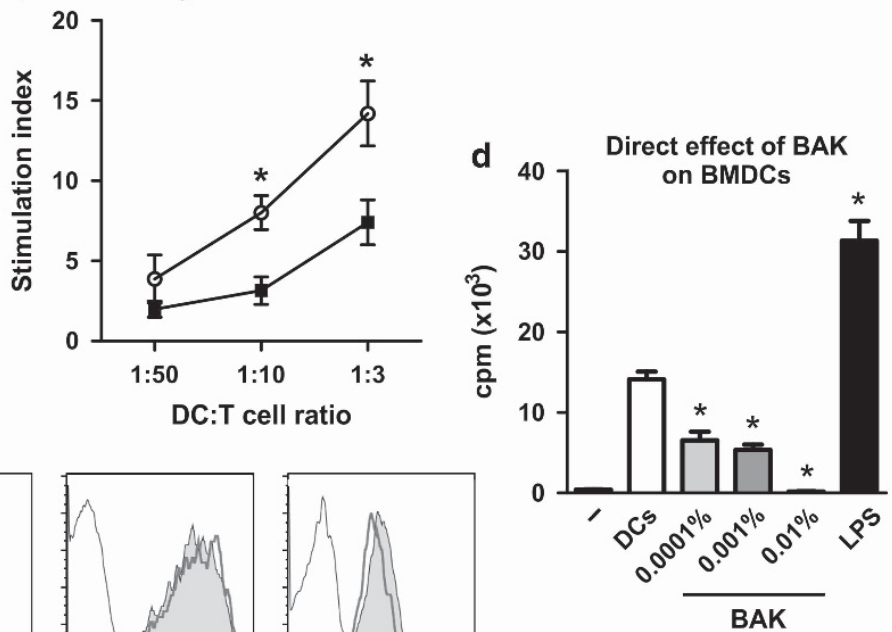

Figure 3 Benzalkonium chloride (BAK) increases the T-cell stimulating capacity and modifies the phenotype of migrating dendritic cells (DCs) by an indirect effect. (a) Representative example $(n=6)$ and mean \pm s.e.m. of $\mathrm{OVA}^{+}$(ovalbumin) cells and their mean fluorescence intensity (MFI) within the $\mathrm{CD} 11 \mathrm{c}^{+} \mathrm{la}^{+}$population of $\mathrm{LN}$ cells from OVA (filled gray histogram and black bars) and OVA+BAK mice $(\mathrm{O}+\mathrm{B}$, black histogram and hatched bars). (b) Allogeneic stimulation assay (mean stimulation index \pm s.e.m.) of isolated DCs from phosphate-buffered saline (PBS; filled squares) or $0.01 \%$ BAK (empty circles) at the specified ratios. (c) Surface molecule expression (mean MFI+s.e.m.) and representative histograms in BAK DCs (thick histograms) relative to PBS-induced cells (filled histograms). Thin histograms represent isotype controls. (d) Allogeneic stimulation capacity (representative example expressed as counts per minute, c.p.m.) of bone marrow-derived DC (BMDC) exposed to different BAK concentrations $(0.0001,0.001$, and $0.01 \%)$ for $15 \mathrm{~min}$. Asterisk indicatesa statistically significant difference, and all experiments were conducted at least three times. ICOSL, inducible T-cell costimulator ligand; LPS, lipopolysaccharide; OVA-FITC, fluorescein-conjugated OVA.

agonists, had similar activity compared with control SNs, and no effect on viability. These results suggest that BAK at 10- and 100 -fold lower concentration than that used in vivo (and probably more representative of what occurs at the eye surface after instillation) does not result in appreciable toxicity but markedly impairs the tolerogenic influence of epithelial cells, as it happens with conjunctival explants from BAK-treated mice.

\section{The immune effect of BAK on epithelial cells is dependent on nuclear factor (NF)- $\kappa B$ activation and impairs their tolerogenic influence on DCs}

As it has been suggested that BAK toxicity involves the specific activation of intracellular signaling pathways, we hypothesized that the observed tolerogenic impairment could implicate the activation of the NF- $\kappa B$ pathway already described for intestinal epithelial cells. To this aim, Pam212 cells were treated with two NF- $\kappa B$ pathway inhibitors (MG132 and sulfasalazine) before exposure to BAK. The activation of this pathway under stress conditions promotes cell survival by preventing apoptosis induction. ${ }^{24}$ Consistent with this, a reduction in cell viability was observed with both inhibitors under all treatment conditions except for the control cells (Figure 5a), suggesting that NF- $\mathrm{kB}$ pathway activation not only occurs with Toll-like receptor agonists, as already described for other epithelial cell types, ${ }^{25}$ but also after BAK exposure. Conditioned SNs were collected and assayed in the previously described way, observing complete abolition of the immunogenic influence of $0.0001 \%$ and $0.001 \%$
BAK-derived SNs on the MLR (Figure 5b). The influence of control- and apoptotic cell-derived SNs was not modified by the inhibitors, suggesting that the activation of the NF- $\mathrm{KB}$ pathway takes place specifically in the preservative-treated cells. These findings highlight a possible role of the NF- $\kappa B$ pathway in the immune effects induced by BAK in epithelial cells.

Moreover, as the priming of T cells at the draining LNs is initiated by migrating DCs, we evaluated the effect of BAK on the conditioning of these APCs by epithelial cells. When we examined the effect of Pam212 SNs on in vitro-generated BMDCs (Figure 6a), we observed that neither control nor BAKderived SNs induced DC maturation, as assessed by allogeneic T-cell proliferation. In fact, all SNs reduced even further the already depressed T-cell stimulation capacity of undifferentiated BMDCs. However, control- and, to a lesser extent, $0.0001 \%$ BAK-derived SNs also inhibited subsequent functional maturation of DCs upon lipopolysaccharide stimulation, whereas those obtained with the two highest BAK concentrations did not so. This experiment shows that only resting epithelial cells induce tolerogenic DCs, whereas BAK-treated epithelia do not, although their conditioned SNs are not sufficient to induce DC maturation. We also observed a significant increase in the proportion of $\mathrm{CD}^{+}{ }^{+} \mathrm{ICOS}^{+}$cells in co-cultures of DO11.10 $\mathrm{T}$ cells with OVA-loaded DCs that had been previously exposed to Pam 212 SNs, irrespectively of whether the epithelial cells were treated with BAK or not before $\mathrm{SN}$ conditioning (Figure 6b,c). These in vitro-conditioned DCs exhibited no 
a
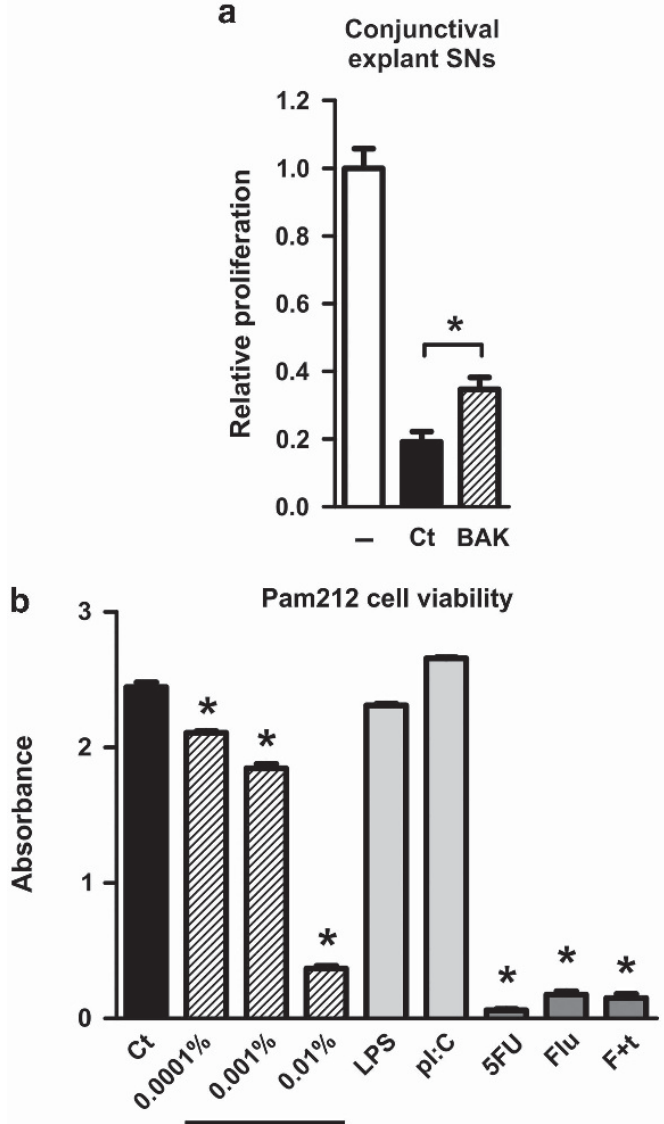

BAK

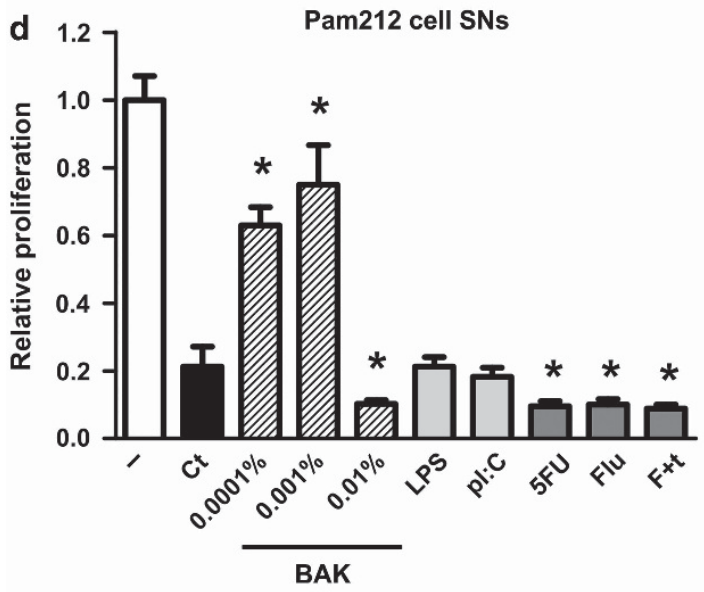

C
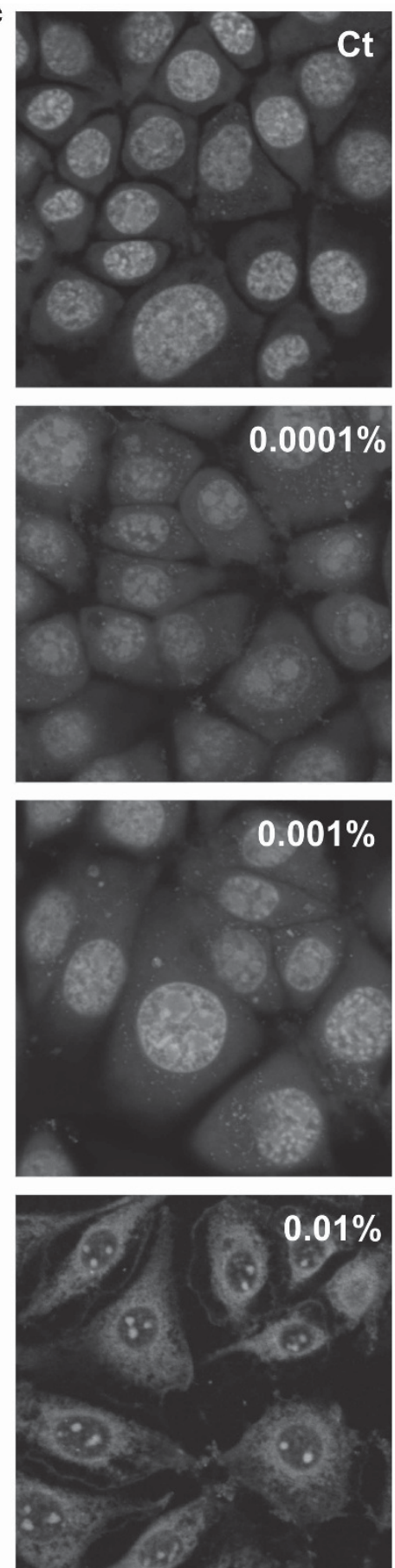

Figure 4 Benzalkonium chloride (BAK) reduces the tolerogenic influence of conjunctival explants and epithelial cells. (a) Effect of conjunctival explant supernatants (SNs) from phosphate-buffered saline- (Ct, black bar) and BAK-treated (BAK, hatched bar) mice on mixed lymphocyte reaction (MLR; mean proliferation \pm s.e.m. relative to control MLR (-, empty bar)). (b) Effect of control medium (Ct), different BAK concentrations (0.0001, 0.001, and $0.01 \%), 1 \mu \mathrm{g} \mathrm{ml}^{-1}$ lipopolysaccharide (LPS), $5 \mu \mathrm{g} \mathrm{ml}^{-1}$ poly l:C (pl:C), $10 \mathrm{mM} 5$-fluorouracil $(5 \mathrm{FU}), 100 \mu \mathrm{M}$ fludarabine (Flu), or freeze/thaw (F+t) cycle on Pam212 cell viability (mean \pm s.e.m. absorbance of cristal violet staining). (c) Representative Pam212 cell morphology (ethidium bromide/ acridine orange staining) after the previously described treatments. (d) Effect of Pam212 SNs obtained after the previously described treatments on $\operatorname{MLR}$ (mean proliferation \pm s.e.m. relative to control MLR (-, empty bar)). For panels $\mathbf{b}$ and $\mathbf{d}$, asterisk indicates a statistically significant difference with the Ct-induced effect.

differences in Ia expression; however, CD86 and ICOSL expression were significantly enhanced by BAK-derived Pam 212 SNs (Figure 6d). These results altogether suggest that BAK exposure impairs the tolerogenic influence exerted by soluble factors released by the epithelial cells on the immune response and particularly on DCs, modifying their phenotype and that of activated $\mathrm{T}$ cells in a similar fashion to what we previously observed in the in vivo model. 

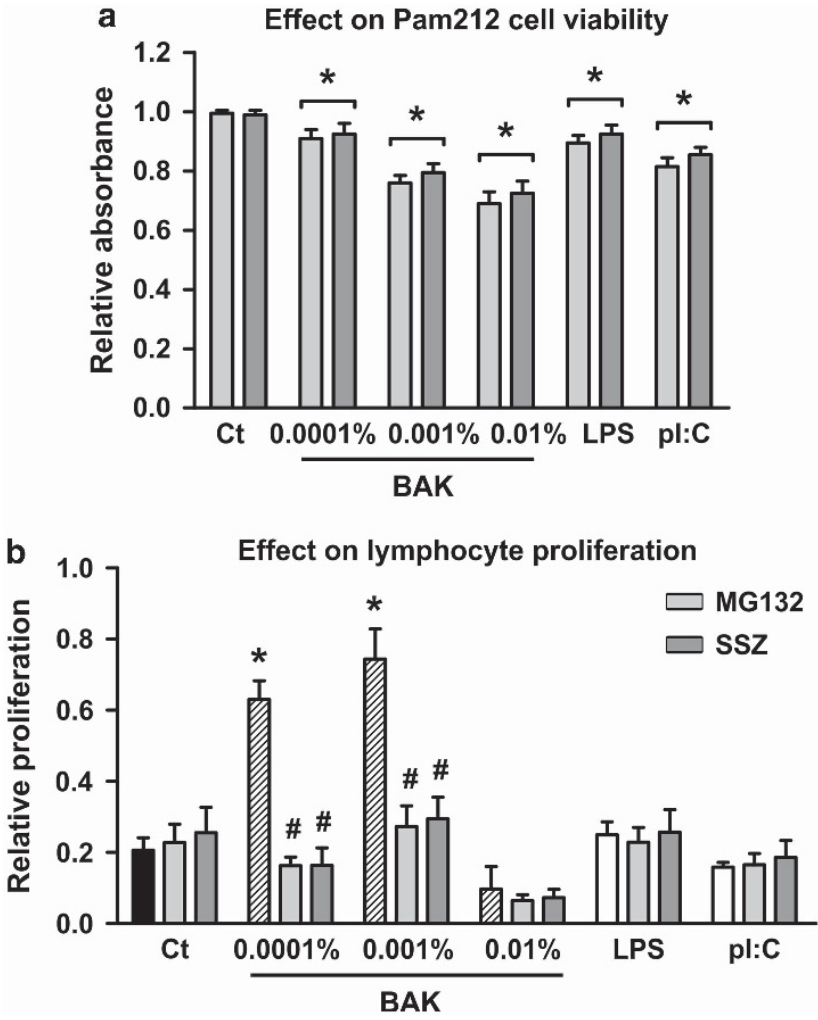

Figure 5 The effect of benzalkonium chloride (BAK) in epithelial cells is dependent on nuclear factor (NF)-кB pathway activation. Pam212 monolayers were cultured for $4 \mathrm{~h}$ with $25 \mu \mathrm{M}$ MG132 (light gray bars) or $5 \mathrm{mM}$ sulfasalazine (SSZ, dark gray bars) before exposure to different BAK concentrations $(0.0001,0.001$, and $0.01 \%$, hatched bars) or concomitantly with lipopolysaccharide (LPS) or poly I:C (pl:C) stimulation. Supernatants (SNs) were obtained as previously described and viability was assessed after $24 \mathrm{~h}$ of SN conditioning. (a) Cell viability (relative absorbance \pm S.e.m. of each treatment + NF- $\kappa B$ inhibitor combination expressed relative to the absorbance of the treatment alone, as assessed by cristal violet staining). Asterisk indicates a statistically significant difference with the treatment alone. (b) Effect of SNs on mixed lymphocyte reaction (MLR; mean proliferation \pm s.e.m. relative to control MLR, not depicted). Asterisk indicates a statistically significant difference with the $\mathrm{Ct} \mathrm{SN}$, whereas \# indicates a significant effect of the inhibitor.

\section{DISCUSSION}

In this work, we show that ocular instillation of BAK in mice has a profound effect on the immune status of the conjunctiva as it impairs tolerance induction to a harmless antigen, and more specifically, prevents the tolerogenic conditioning of DCs by epithelial cells. This widely used eye drop preservative has numerous deleterious effects on the eye surface, but to the best of our knowledge, this is the first description of functional immune impact of this compound. From these results, we propose that this newly reported effect of BAK may be of importance in the management of glaucoma and ocular surface disease, and thus should be appropriately considered.

Conjunctival tolerance was first described by Egan et al. ${ }^{10}$ in mice, highlighting the importance of antigen-specific $\mathrm{CD} 4^{+}$ T-cell proliferation in the local LN. In a similar model, we observed that conjunctival administration of antigen induces suppressive Foxp $3^{-} \mathrm{ICOS}^{+} \mathrm{T}$ cells with the capacity to secrete
IL-10, a profile consistent with that reported for Tr1 regulatory cells. ${ }^{26,27}$ Sundstedt et al. ${ }^{28}$ previously described similar findings for $\mathrm{CD}^{+}{ }^{+}$cells induced after intranasal delivery of peptide, and the conjunctiva-associated lymphoid tissue, although functionally independent, shares many characteristics with the nasal immune system. ${ }^{29}$ We observed that concomitant BAK administration (at the same concentration used in eye drops approved for human use, up to $0.02 \%$ ) prevents the development of immune tolerance to a specific antigen by impairing induction of these suppressive $T$ cells. Instead, the preservative leads to mild immunization mediated by non-suppressive $\mathrm{ICOS}^{+}$effector $\mathrm{T}$ cells, which could be of relevance in chronic conjunctival disorders by potentiating subclinical inflammation, and more importantly, for long-term glaucoma treatments with preserved eyedrops. In the literature, $\mathrm{ICOS}^{+} \mathrm{T}$ cells have been implicated in asthma ${ }^{30}$ and seem to produce Th 2 cytokines, ${ }^{27}$ although our findings are insufficient to delineate a specific $\mathrm{T}$-cell profile induced by BAK exposure. In both the basal tolerogenic and the BAK-induced immunogenic settings in our model, the generated $\mathrm{CD} 4^{+}$cells recirculated widely in the lymphoid tissues, supporting the need for systemic treatment in the more severe forms of immune-mediated eye surface disease.

Regarding the mechanism underlying the breakdown in conjunctival tolerance, BAK is known to enhance the penetration of acyclovir and gatifloxacin by affecting the epithelial barrier. ${ }^{31,32}$ Thus, greater OVA amounts reaching the conjunctival antigenpresenting cells could be accounted for the difference in tolerance or immunization, as antigen dose is known to determine the mechanism of oral tolerance. ${ }^{33}$ However, facilitated antigen delivery to conjunctival DCs does not seem to be relevant in our model as the number of antigen-presenting cells and the amount of antigen in the draining LNs are not increased by BAK exposure. Nevertheless, DCs influenced by the preservative had different functional and phenotypical properties when purified from the draining LNs, suggesting a role for BAK in DC conditioning before emigration from the conjunctiva. Augmented ICOSL expression in DCs from OVA-treated mice is consistent with the tolerance-induction mechanisms reported for the respiratory mucosa, ${ }^{34}$ perhaps because the conjunctiva is more closely akin to nasal and bronchial linings than to the gastrointestinal mucosa. Thus, the enhanced Ia expression, and more importantly, the decrease in ICOSL costimulatory signal observed in OVA + BAK-induced DCs could explain the abrogation of tolerance and the development of an immunogenic response instead. Overall, our findings with ex vivo DCs are in agreement with the epithelial programming of these APCs in tolerogenic and immunogenic mucosal responses. ${ }^{16,19}$ In the conjunctiva, BAK induces apoptosis and necrosis of the epithelial cells both in vivo ${ }^{35}$ and in vitro ${ }^{4}$ after exposure at the commercially used concentration, and also increases the epithelial release of proinflammatory cytokines such as IL- 6 and IL-8. ${ }^{7}$ In agreement with these reports, conjunctival explants from BAK-treated mice produced a different combination of soluble factors that resulted in less impairment of the MLR. In contrast, conjunctival explant SNs from control nice markedly inhibited the allogeneic reaction, in line with the widely 


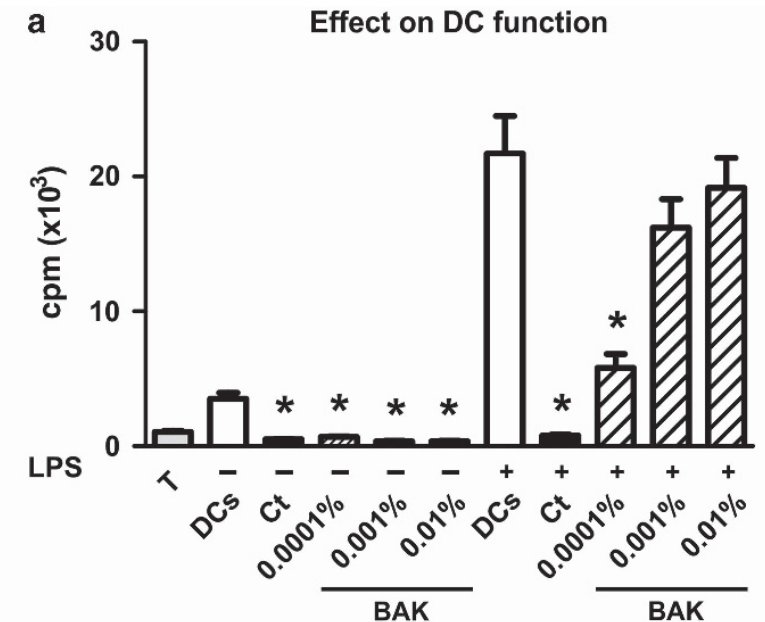

b

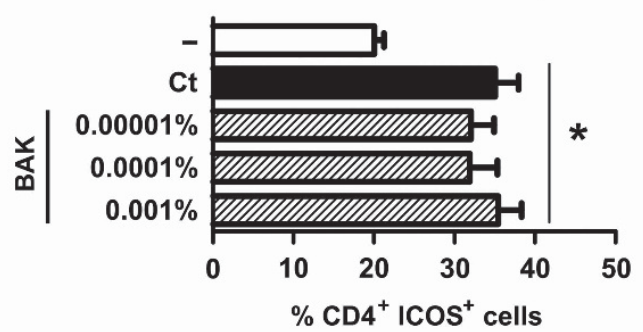

d

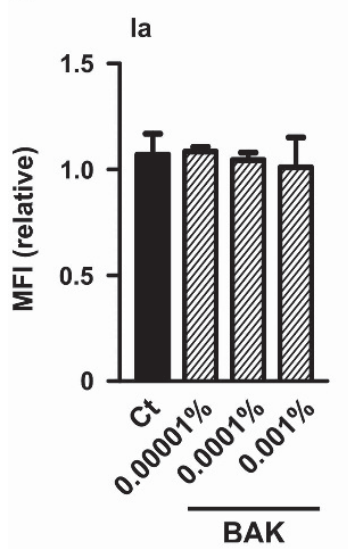

Effect on DC phenotype

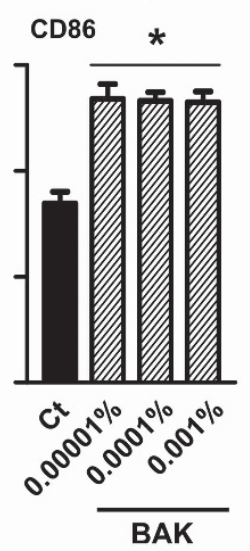

C
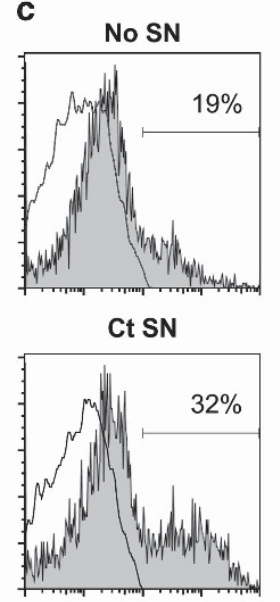

SN BAK $0.00001 \%$

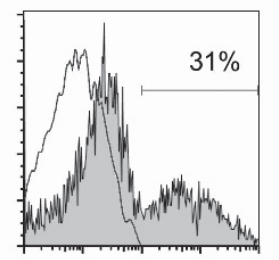

SN BAK $0.0001 \%$

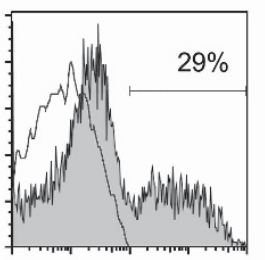

SN BAK $0.001 \%$

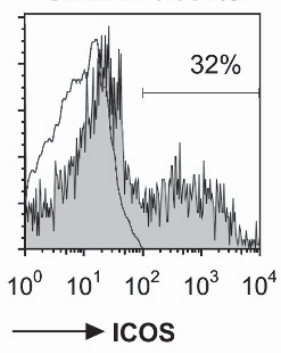

Figure 6 Epithelial supernatants (SNs) modulate dendritic cell (DC) phenotype and function. Bone marrow-derived DC were differentiated for 48h in medium (DCs) or in the presence of the previously described Pam212 SNs. Lipopolysaccharide (LPS) was added to some cultures for the last 24h. (a) Allogeneic stimulation capacity (representative example expressed as counts per minute, c.p.m.) of these DCs. T shows the proliferation of allogeneic T cells alone, whereas DCs indicates control cells with medium. (b and c) Inducible T-cell costimulator (ICOS) expression (mean percentage of ICOS ${ }^{+}$cells \pm s.e.m. and representative examples as filled histograms) in DO11.10 CD4 ${ }^{+}$cells cultured for 3 days with ovalbumin-pulsed BMDCs described in a. Cultures with control DCs are shown as - or No SN, with isotype controls as empty histograms. Gates show proportion of ICOS ${ }^{+}$cells. (d) Expression of surface molecules (mean fluorescence intensity (MFI) \pm s.e.m. relative to control cells) in SN-conditioned BMDCs. Asterisk indicates a statistically significant difference. BAK, benzalkonium chloride.

described tolerogenic influence of epithelial cells from other mucosal sites on the immune response. ${ }^{16}$

Conjunctival epithelial cells share many morphological features with skin keratinocytes, ${ }^{36}$ and given the lack of commercially available murine epithelial cell lines from conjunctival origin, the widely studied keratinocyte cell line Pam $212^{21}$ represents a suitable replacement for the study of the immune impact of BAK exposure. Validating this hypothesis, in vitrogrown keratinocytes also released inhibitory factors as did the ex vivo conjunctival explants, suggesting that there is a common underlying tolerogenic influence on the immune response regardless of the epithelial site. Additionally, Pam212 cells exhibited a BAK toxicity profile similar to those reported for human conjunctival cell lines. ${ }^{22}$ The commercially used BAK 
concentration induced extensive death of the epithelial cells, as has already been described, but the lower concentrations were not conducive to significant apoptosis or necrosis. These reduced BAK levels probably better represent the in vivo exposure as there are several factors that could rapidly lower the preservative concentration: dilution in the tear film, induced tear secretion, and physiological tear clearance. In contrast to $0.01 \% \mathrm{BAK}$, the lower preservative concentrations impaired the suppressive influence of the epithelial SNs without significantly affecting cell viability, suggesting the involvement of a specific immune pathway. Moreover, this immune effect was entirely dependent on NF- $\kappa \mathrm{B}$ pathway activation in the epithelial cells. This pathway has a crucial role in tolerance induction at other mucosal sites, ${ }^{37}$ and to the best of our knowledge, this is the first reported evidence linking BAK toxicity and NF- $\kappa B$ pathway activation. Of note, although Toll-like receptor agonists are known activators of NF- $\mathrm{\kappa B}$ and were able to modulate Pam 212 cell viability when this pathway was specifically inhibited, they did not modify the immune effect of Pam212 SNs, suggesting the involvement of additional signaling pathways recruited by BAK. In line with this, Zhou et al. ${ }^{23}$ recently reported that BAK toxicity is dependent on the activation of the Wnt pathway in epithelial cells. Moreover, our findings are in agreement with theirs in that the NF- $\kappa \mathrm{B}$ and Wnt pathways are known to crosstalk in other epithelial cell types. ${ }^{38,39}$

Our finding that BAK impaired the tolerogenic influence of epithelial cells on DC could be relevant in eye surface disease as conditioning of these APCs is crucial in other mucosal chronic inflammatory disorders. ${ }^{18,19}$ Supporting this idea, we could partially reproduce the observed phenotypical differences in ex vivo DCs by culturing BMDCs in the presence of Pam 212 SNs. All epithelial SNs increased the proportion of $\mathrm{CD}^{+} \mathrm{ICOS}^{+}$cells, whereas only BAK-derived SNs led to enhanced costimulatory signaling on DCs. The incompletely corresponding expression profiles of ex vivo- and in vitro-conditioned DCs highlight the fact that conjunctival epithelial influence exerted through soluble factors is probably not the only pathway implicated in tolerogenic and immunogenic responses. Accordingly, Illiev et al. ${ }^{18}$ found that actual contact with intestinal epithelial cells bestowed increased CD103 expression upon DCs, although soluble factor conditioning was sufficient to confer a tolerogenic profile on these APCs.

In summary, we have collected evidence from a murine model that suggests that the observed BAK toxicity in human use could be aggravated by an inhibitory effect on conjunctival tolerance. Although we gained considerable insight into the types of $\mathrm{T}$ cells and the functional characteristics of conjunctival APCs, the specific nature of the epithelium-derived factors involved in this phenomenon remains to be identified. Nevertheless, we believe that these findings are sufficient to raise at least two important issues in ophthalmic practice: in the one hand, the profound conjunctival immunological changes expected in glaucoma patients, and on the other hand, the long-term impact of an allegedly anti-inflammatory treatment that could severely impair the tolerogenic function of the eye surface. More work in this area is warranted to elucidate new treatments and better ways to approach ocular surface disorders.

\section{METHODS}

Mice. Female C57BL6J or BALB/c mice (8-12-weeks old), which were bred and maintained in our conventional animal facility, were used for the in vivo experiments to account for strain-specific differences and then all subsequent experiments were performed in Balb/c mice. $\mathrm{DO} 11.10 \mathrm{Balb} / \mathrm{c}$ (OVA-specific transgenic TCR) mice were kindly provided by Prof. O. Campetella (University of San Martín, Buenos Aires, Argentina) and maintained in microisolator cages in our pathogenfree animal facility. All experiments were approved by the institution's animal ethics committee.

Reagents and antibodies. All chemical and biological reagents used were from Sigma-Aldrich (Buenos Aires, Argentina) unless otherwise specified. Anti-CD3, -CD4, -CD11c, -CD19, -IL-4, -IL-10, -IL-17A, -IFN $\gamma$, -ICOS, -ICOSL, and -Foxp3 antibodies were from BioLegend (San Diego, CA). Grade V OVA (Sigma-Aldrich) was used in all experiments, and specifically for cell tracking, it was previously coupled to fluorescein according to the manufacturer's instructions.

Conjunctival administration of BAK and OVA, parenteral immunization and adoptive transfer of mice. Mice received phosphate-buffered saline (PBS), $0.01 \%$ BAK, $10 \mu \mathrm{g}$ of OVA $\left(2 \mathrm{mg} \mathrm{ml}^{-1}\right)$, or combination of both (OVA + BAK) in PBS administered topically in a volume of $5 \mu \mathrm{l}$ to the conjunctiva of both eyes for 5 or 10 days, as indicated in the figure legends. On day 7 or 14 , either $0.5 \mathrm{ml}$ of $400 \mu \mathrm{g} \mathrm{ml}^{-1} \mathrm{OVA}+4 \mathrm{mg} \mathrm{ml}^{-1}$ aluminum hydroxide suspension was injected intraperitoneally or $0.1 \mathrm{ml}$ of 1:1 PBS:complete Freund's adjuvant emulsion containing 100 $\mu \mathrm{g}$ OVA was injected subcutaneously in the back. For the adoptive transfer experiments, pooled splenic and LN CD4 ${ }^{+}$cells from DO11.10 mice were obtained as described below for T-cell proliferation assays, and $20 \times 10^{6}$ cells in $0.5 \mathrm{ml}$ PBS were intraperitoneally injected to each Balb/c mouse. Conjunctival instillation was started $4 \mathrm{~h}$ after the adoptive transfer.

Measurement of delayed-type hypersensitivity and antibody responses. BAK, OVA, and OVA + BAK were administered to the conjunctiva of groups of three mice, as described in the figure legends. In the case of delayed-type hypersensitivity, OVA $(100 \mu \mathrm{g})$ in $0.1 \mathrm{ml}$ of $1: 1$ complete Freund's adjuvant emulsion was injected subcutaneously in the back and flanks on day 8 . A group of unmanipulated (naïve) BALB/c mice served as a negative control. On day 15, OVA (100 $\mu \mathrm{g}$ in PBS) and PBS alone were injected in a volume of $10 \mu \mathrm{l}$ into the right and left foot pads, respectively. Foot pad swelling was measured 24 and $48 \mathrm{~h}$ later and expressed as the mean ( \pm s.e.m.) difference between right and left foot pads for each group. For antibody responses and starting at day 0 , mice were bled weekly from a tail vein for heparinized plasma collection. Mice were immunized likewise on day 15 and sampled for 6 weeks. OVAspecific antibody levels were determined by direct enzyme-linked immunosorbent assay in antigen-coated microtiter plates with serum dilutions in triplicates and using biotin-conjugated rat anti-mouse Ig $\kappa$ light chain antibody (BD Biosciences, San Jose, CA) for detection. Results are expressed as mean absorbance values.

Cell lines and cultures. All cell cultures were performed in Iscove's modified Dulbecco's medium supplemented with $10 \%$ fetal calf serum, $10 \mathrm{mM}$ glutamine, $100 \mathrm{U} \mathrm{ml}^{-1}$ penicillin, $100 \mu \mathrm{g} \mathrm{ml}^{-1}$ streptomycin, and $5 \times 10^{-5} \mathrm{M} 2$-mercaptoethanol in a humidified incubator with $5 \% \mathrm{CO}_{2}$ at $37^{\circ} \mathrm{C}$. The Pam 212 cell line, which was originally derived from murine epidermal keratinocytes, ${ }^{21}$ was a kind gift from Dr Casas (Hospital de Clínicas, University of Buenos Aires, Buenos Aires, Argentina) and was maintained in the same medium.

Flow cytometry. For surface antigens, cells were washed in PBS with $0.5 \%$ bovine serum albumin (flow cytometry buffer) in the cold, incubated for $15 \mathrm{~min}$ with $5 \mu \mathrm{g} \cdot \mathrm{ml}^{-1} 2.4 \mathrm{G} 2$ antibody (purified from ascites fluid) to block non-specific binding to Fc $\gamma$ receptors and then fluorochromeconjugated antibodies at previously titrated concentrations were added 
without washing for another $30 \mathrm{~min}$. Finally, cells were thoroughly washed in PBS with $1 \mathrm{mM}$ ethylenediaminetetraacetic acid before acquisition on a FACScalibur cytometer (Becton Dickinson, Buenos Aires, Argentina). Data were analyzed with CellQuest (Becton Dickinson, Argentina) or FlowJo (TreeStar, Ashland, OR) software. Optimal compensation and gain settings, as well as viable cell gating, were determined as previously described. ${ }^{40}$ Overlayed histogram graphs are plotted in normalized form as percentage of maximum for each histogram.

In vitro $\mathrm{DC}$ cultures and ex vivo isolation. $\mathrm{BMDCs}$ were generated from bone marrow cultures of C57/BL6J or BALB/c mice in the presence of $25 \%$ SN from granulocyte-macrophage colony-stimulating factorproducing NIH-3T3 cells. ${ }^{41}$ On day 7, nonadherent and loosely adherent cells were harvested as BMDCs. The purity of the DCs, determined by flow cytometry analysis of surface CD11c staining, was $>60 \%$. In some experiments, BMDCs were matured in vitro by culturing overnight in the presence of $100 \mathrm{ng} \mathrm{ml}^{-1}$ lipopolysaccharide. For DC conditioning, BMDC cultures were switched on day 6 to fresh medium with 25\% epithelial SNs and on day 7 lipopolysaccharide was added. In all cases, BMDCs were extensively washed before adding them to T-cell cultures.

For ex vivo DC characterization, groups of three mice or more were treated once with PBS and BAK or with OVA-FITC ${ }^{+}$with or without $\mathrm{BAK}$, and the draining LNs were collected $18 \mathrm{~h}$ later. Cell suspensions were prepared by $1 \mathrm{mg} \mathrm{ml}^{-1}$ collagenase treatment (Roche, Tigre, Argentina) for $1 \mathrm{~h}$ at $37^{\circ} \mathrm{C}$ and then washed in complete medium. Purification of CD $11 \mathrm{c}^{+}$ cells was carried out with MACS paramagnetic beads (Miltenyi Biotec, Buenos Aires, Argentina), according to the manufacturer's instructions.

T-cell proliferation assays. Cell suspensions were obtained by mechanical dissociation through wire mesh from spleens or conjunctiva-draining submandibular LNs from groups of 3-6 mice. For antigen proliferation assays, $5 \times 10^{5}$ cells were seeded in 96 -well plates containing $100 \mu \mathrm{g} \mathrm{ml}^{-1}$ OVA. Cultures were incubated for 3 days with the addition of $1 \mu \mathrm{Ci}$ per well $\left[{ }^{3} \mathrm{H}\right]$-thymidine for the final $24 \mathrm{~h}$, and incorporation was measured by liquid scintillation counting. ${ }^{41}$ Briefly, cells were collected on filterpaper discs with the aid of a semiautomatic harvester, and $\left[{ }^{3} \mathrm{H}\right]$-thymidine incorporation was determined in a Wallac 1414 Winspectral beta scintillation counter (PerkinElmer, Buenos Aires, Argentina). Results of triplicate or quadruplicate cultures are expressed as the mean stimulation index \pm s.e.m., calculated as the ratio of counts per minute in antigen-containing cultures to the counts in control cultures. ${ }^{40}$ For MLR and allogeneic DC cultures, splenic or LN CD $4^{+}$cells ( $>90 \%$ purity) were isolated from with MACS paramagnetic beads (Miltenyi Biotec, Germany), while CD3 ${ }^{+}$ cell-depleted fractions (stimulating cells, $<5 \% \mathrm{CD} 4^{+}$and $\mathrm{CD} 8^{+}$cells) were prepared from cell suspensions with purified anti-CD3 antibody and magnetic beads (Pierce, Rockford, IL), following the manufacturer's instructions. For MLR cultures, $2.5 \times 10^{5} \mathrm{CD}^{+}$splenocytes were added to the same number of mitomycin C-treated, allogeneic-stimulating cells. For allogeneic DC cultures, the specified number of DCs was added to $5 \times 10^{5}$ allogeneic $\mathrm{CD}^{+}$splenocytes. In both cases, cultures were incubated for 5 days, pulsed likewise with $\left[{ }^{3} \mathrm{H}\right]$-thymidine and the stimulation index was calculated relative to the counts of responding $\mathrm{CD} 4^{+}$cells alone. For suppression curves, the specified ratios of splenic or LN CD4 ${ }^{+}$ cells were added to $2.5 \times 10^{5}$ splenocytes from an OVA-immunized mouse and cultured for 3 days in the presence of antigen. Stimulation indices were calculated as described above and the results are expressed relative to the stimulation indices obtained when $\mathrm{CD} 4{ }^{+}$cells from unmanipulated mice were added under the same conditions.

Intracellular cytokine and Foxp3 staining. For intracellular cytokine detection in in vitro amplified OVA-specific T cells, LN cells were cultured for 7 days with OVA-pulsed DCs $\left(100 \mu \mathrm{g} \mathrm{ml}^{-1}\right.$ OVA for $\left.4 \mathrm{~h}\right)$ at a 10:1 cell ratio, and then restimulated with the same number of antigenloaded DCs for $18 \mathrm{~h}$ in the presence of $10 \mu \mathrm{g} \mathrm{ml}^{-1}$ brefeldin A. For similar assays directly performed with ex vivo LN cells (Balb/c mice with or without adoptively transferred DO11.10 T cells), cells were seeded at low density for $12 \mathrm{~h}$ in the presence of $10 \mu \mathrm{g} \mathrm{ml}^{-1}$ brefeldin A in cultures plates that were previously adsorbed with $100 \mu \mathrm{g} \mathrm{ml}^{-1}$ anti-CD3 antibody. Then cells were collected, fixed with $4 \%$ paraformaldehyde for $30 \mathrm{~min}$ at room temperature, washed with $0.2 \mathrm{M}$ glycine, and made permeable with buffer containing $0.1 \%$ saponin and $5 \%$ fetal calf serum for $30 \mathrm{~min}$. Phycoerythrin-conjugated anti-cytokine antibodies and matching isotype controls were finally added in this permeabilization buffer for $30 \mathrm{~min}$ at room temperature, washed twice in the same buffer, and finally prepared for flow cytometry. For Foxp 3 intracellular staining, cells were stained for surface markers and then fixed, permeabilized, stained with phycoerythrin-conjugated anti-Foxp3 antibody, and finally washed with Foxp3 Fix/Perm buffer set (BioLegend), as recommended by the manufacturer.

Conjunctival explants and Pam212 cell cultures. The tarsal conjunctivas from PBS- or BAK-treated mice were excised under aseptic conditions with the aid of a dissection microscope. In detail, each mouse was killed and laid on its ventral side before wetting the head's skin with $70 \%$ ethanol and immediately rinsing with PBS. A midline incision along the cranial skin was performed with iris scissors and then extended around each eye, leaving a periocular skin rim, which was everted to allow delineation of the translucent tarsal conjunctiva from the opaque subcutaneous surface of the periocular skin. Careful excision of this remaining rim of periocular skin was performed along the thicker palpebral margins, and then the tarsal conjunctiva was excised by grasping from its now freed margin and cutting along the bony orbital rim, carefully avoiding damaging the now superficially exposed orbital sinus (to prevent profuse bleeding). The excised conjunctival explants from each animal (approximately $30 \mathrm{mg}$ of tissue) were pooled, washed three times in PBS, and then cultured in $1 \mathrm{ml}$ of medium without serum. Supernatants were collected after $24 \mathrm{~h}$ for further analysis.

Pam 212 cells were cultured until confluent in 12-well plates and then exposed to fresh medium alone or with $0.0001,0.001$, or $0.01 \%$ BAK for $15 \mathrm{~min}$ at $37^{\circ} \mathrm{C}$, washed twice, and finally cultured in $1 \mathrm{ml}$ fresh medium without serum. After overnight culture, SNs were collected and viability of remaining cells was assessed by crystal violet staining. Briefly, cell monolayers were washed twice with PBS, then covered with $0.5 \% \mathrm{~m} / \mathrm{v}$ crystal violet in $20 \%$ methanol for $30 \mathrm{~min}$ at room temperature, and finally rinsed by careful immersion in excess distilled water to avoid dislodging the cells. After air-drying the culture plates overnight, $30 \%$ acetic acid was added to each well to solubilize the remaining adherent cells and each SN's absorbance was determined with a spectrophotometer. For some experiments, NF- $\kappa \mathrm{B}$ activation inhibitors and Toll-like receptor agonists were added at the indicated concentrations $4 \mathrm{~h}$ in advance of BAK treatment and washed immediately before preservative exposure. For others assays, Pam 212 monolayers were frozen and then left to thaw or cultured for $18 \mathrm{~h}$ in the presence of 5 -fluorouracil or fludarabine, and then profusely washed before adding fresh medium. Supernatants in DC conditioning and MLR experiments were assayed at $25 \%$ concentration in culture.

Statistical analysis. Student's $t$-test and analysis of variance with Bonferroni's post hoc test were used to compare means of two and three or more samples, respectively. Significance was set at $P<0.05$ (two-tailed tests) and calculations were performed using GraphPad Prism 5 software (GraphPad Software, La Jolla, CA).

SUPPLEMENTARY MATERIAL is linked to the online version of the paper at http://www.nature.com/mi

\section{ACKNOWLEDGMENTS}

We gratefully acknowledge financial support from Fundación Florencio Fiorini, Buenos Aires, Argentina and the National Academy of Medicine, Buenos Aires, Argentina. We thank Professor O. Campetella (University of San Martín, Buenos Aires) for providing DO11.10 mice and the IMEX animal facility staff for their excellent assistance. 


\section{DISCLOSURE}

The authors declared no conflict of interest.

(C) 2013 Society for Mucosal Immunology

\section{REFERENCES}

1. Moss, S.E., Klein, R. \& Klein, B.E. Prevalence of and risk factors for dry eye syndrome. Arch. Ophthalmol. 118, 1264-1268 (2000).

2. Baudouin, C. The pathology of dry eye. Surv. Ophthalmol. 45 (Suppl 2), S211-S220 (2001).

3. Baudouin, C., Labbe, A., Liang, H., Pauly, A. \& Brignole-Baudouin, F. Preservatives in eyedrops: the good, the bad and the ugly. Prog. Retin. Eye Res. 29, 312-334 (2010).

4. De Saint Jean, M. et al. Effects of benzalkonium chloride on growth and survival of Chang conjunctival cells. Invest. Ophthalmol. Vis. Sci. 40, 619-630 (1999).

5. Manni, G., Centofanti, M., Oddone, F., Parravano, M. \& Bucci, M.G. Interleukin-1 beta tear concentration in glaucomatous and ocular hypertensive patients treated with preservative-free nonselective betablockers. Am. J. Ophthalmol. 139, 72-77 (2005).

6. Massingale, M.L. et al. Analysis of inflammatory cytokines in the tears of dry eye patients. Cornea 28, 1023-1027 (2009).

7. Baudouin, C. et al. Conjunctival epithelial cell expression of interleukins and inflammatory markers in glaucoma patients treated over the long term. Ophthalmology 111, 2186-2192 (2004).

8. Baudouin, C. et al. CCR 4 and CCR 5 expression in conjunctival specimens as differential markers of $\mathrm{T}(\mathrm{H}) 1 / \mathrm{T}(\mathrm{H}) 2$ in ocular surface disorders. J. Allergy Clin. Immunol. 116, 614-619 (2005).

9. Liang, H., Baudouin, C., Labbe, A., Riancho, L. \& Brignole-Baudouin, F. Conjunctiva-Associated Lymphoid Tissue (CALT) Reactions to Antiglaucoma Prostaglandins with or without BAK-Preservative in Rabbit Acute Toxicity Study. PLoS One 7, e33913 (2012).

10. Egan, R.M. et al. In vivo behavior of peptide-specific T cells during mucosal tolerance induction: antigen introduced through the mucosa of the conjunctiva elicits prolonged antigen-specific $T$ cell priming followed by anergy. J. Immunol. 164, 4543-4550 (2000).

11. Unger, W.W. et al. Early events in peripheral regulatory T cell induction via the nasal mucosa. J. Immunol. 171, 4592-4603 (2003).

12. Pabst, O., Bernhardt, G. \& Forster, R. The impact of cell-bound antigen transport on mucosal tolerance induction. J. Leukoc. Biol. 82, 795-800 (2007).

13. Swamy, M., Jamora, C., Havran, W. \& Hayday, A. Epithelial decision makers: in search of the 'epimmunome'. Nat. Immunol. 11, 656-665 (2010).

14. Rimoldi, M. et al. Monocyte-derived dendritic cells activated by bacteria or by bacteria-stimulated epithelial cells are functionally different. Blood 106, 2818-2826 (2005).

15. Idzko, M. et al. Extracellular ATP triggers and maintains asthmatic airway inflammation by activating dendritic cells. Nat. Med. 13, 913-919 (2007).

16. Rimoldi, M. et al. Intestinal immune homeostasis is regulated by the crosstalk between epithelial cells and dendritic cells. Nat. Immunol. 6, 507-514 (2005).

17. Hammad, H. \& Lambrecht, B.N. Dendritic cells and epithelial cells: linking innate and adaptive immunity in asthma. Nat. Rev. Immunol. 8, 193-204 (2008).

18. Iliev, I.D., Mileti, E., Matteoli, G., Chieppa, M. \& Rescigno, M. Intestinal epithelial cells promote colitis-protective regulatory T-cell differentiation through dendritic cell conditioning. Mucosal. Immunol. 2, 340-350 (2009).

19. Iliev, I.D. et al. Human intestinal epithelial cells promote the differentiation of tolerogenic dendritic cells. Gut 58, 1481-1489 (2009).

20. Wolvers, D.A., van der Cammen, M.J. \& Kraal, G. Mucosal tolerance is associated with, but independent of, up-regulation Th2 responses. Immunology 92, 328-333 (1997).
21. Yuspa, S.H., Hawley-Nelson, P., Koehler, B. \& Stanley, J.R. A survey of transformation markers in differentiating epidermal cell lines in culture. Cancer Res. 40, 4694-4703 (1980).

22. Brasnu, E., Brignole-Baudouin, F., Riancho, L., Warnet, J.M. \& Baudouin, C. Comparative study on the cytotoxic effects of benzalkonium chloride on the Wong-Kilbourne derivative of Chang conjunctival and IOBA-NHC cell lines. Mol. Vis. 14, 394-402 (2008).

23. Zhou, Y. et al. Modulation of the canonical Wnt pathway by benzalkonium chloride in corneal epithelium. Exp. Eye Res. 93, 355-362 (2011).

24. Yokoyama, S. et al. Enhancement of ultraviolet-induced apoptosis by NF-kappaB decoy oligonucleotides. Br. J. Dermatol. 153 (Suppl 2), 47-51 (2005).

25. Haddad, J.J. \& Land, S.C. Amiloride blockades lipopolysaccharideinduced proinflammatory cytokine biosynthesis in an IkappaB-alpha/ NF-kappaB-dependent mechanism. Evidence for the amplification of an antiinflammatory pathway in the alveolar epithelium. Am. J. Respir. Cell Mol. Biol. 26, 114-126 (2002).

26. Vieira, P.L. et al. IL-10-secreting regulatory T cells do not express Foxp3 but have comparable regulatory function to naturally occurring CD4+CD25+ regulatory T cells. J. Immunol. 172, 5986-5993 (2004).

27. Lohning, M. et al. Expression of ICOS in vivo defines CD4+ effector T cells with high inflammatory potential and a strong bias for secretion of interleukin 10. J. Exp. Med. 197, 181-193 (2003).

28. Sundstedt, A., O'Neill, E.J., Nicolson, K.S. \& Wraith, D.C. Role for IL-10 in suppression mediated by peptide-induced regulatory T cells in vivo. J. Immunol. 170, 1240-1248 (2003).

29. Chentoufi, A.A. et al. Nasolacrimal duct closure modulates ocular mucosal and systemic CD4(+) T-cell responses induced following topical ocular or intranasal immunization. Clin. Vaccine Immunol. 17, 342-353 (2010).

30. Tesciuba, A.G. et al. Inducible costimulator regulates Th2-mediated inflammation, but not Th2 differentiation, in a model of allergic airway disease. J. Immunol. 167, 1996-2003 (2001).

31. Rathore, M.S. \& Majumdar, D.K. Effect of formulation factors on in vitro transcorneal permeation of gatifloxacin from aqueous drops. AAPS Pharm. Sci. Tech. 7, 57 (2006).

32. Majumdar, S., Hippalgaonkar, K. \& Repka, M.A. Effect of chitosan, benzalkonium chloride and ethylenediaminetetraacetic acid on permeation of acyclovir across isolated rabbit cornea. Int. J. Pharm. 348, 175-178 (2008).

33. Friedman, A. \& Weiner, H.L. Induction of anergy or active suppression following oral tolerance is determined by antigen dosage. Proc. Natl. Acad. Sci. USA 91, 6688-6692 (1994).

34. Akbari, O. et al. Antigen-specific regulatory T cells develop via the ICOSICOS-ligand pathway and inhibit allergen-induced airway hyperreactivity. Nat. Med. 8, 1024-1032 (2002).

35. Dogan, A.S., Orhan, M., Soylemezoglu, F., Irkec, M. \& Bozkurt, B. Effects of topical antiglaucoma drugs on apoptosis rates of conjunctival epithelial cells in glaucoma patients. Clin. Exp. Ophthalmol. 32, 62-66 (2004).

36. Sun, T.T. \& Green, H. Cultured epithelial cells of cornea, conjunctiva and skin: absence of marked intrinsic divergence of their differentiated states. Nature 269, 489-493 (1977).

37. Zaph, C. et al. Epithelial-cell-intrinsic IKK-beta expression regulates intestinal immune homeostasis. Nature 446, 552-556 (2007).

38. Sun, J. et al. Crosstalk between NF-kappaB and beta-catenin pathways in bacterial-colonized intestinal epithelial cells. Am. J. Physiol. Gastrointest. Liver Physiol. 289, G129-G137 (2005).

39. Umar, S., Sarkar, S., Wang, Y. \& Singh, P. Functional cross-talk between beta-catenin and NFkappaB signaling pathways in colonic crypts of mice in response to progastrin. J. Biol. Chem. 284, 22274-22284 (2009).

40. Galletti, J. et al. Chronic lymphocytic leukemia cells bind and present the erythrocyte protein band 3: possible role as initiators of autoimmune hemolytic anemia. J. Immunol. 181, 3674-3683 (2008).

41. Amaral, M.M. et al. Thioperamide induces CD4 CD25 Foxp3 regulatory T lymphocytes in the lung mucosa of allergic mice through its action on dendritic cells. J. Asthma Allergy 4, 93-102 (2011). 